\title{
Six Authors and the Saturday Review: A Quantitative Approach to Style
}

\author{
HUGH CRAIG AND ALEXIS ANTONIA
}

The Saturday Review, founded in I 855 , was the most controversial weekly journal in mid-Victorian England. Looking back in I 890, Eliza Lynn Linton, one of its contributors, spoke of the Saturday in these terms: "If the most formidable, it was also the freest paper of its time. [. . .] Sharptongued and hard-hitting as the journal was, and by no means sensitive to tender skins, it was absolutely and proudly independent." John Jump describes it as "younger, fiercer, livelier, and more cocksure than its rivals," with a "talent and taste for slashing and debunking." ${ }^{2}$ It set out to be the "scourge of vulgarity, of bohemianism, of Grub Street, of Dickens, and perhaps most of all of religious enthusiasm," making the powerful Times its special target. ${ }^{3}$ The Baptist preacher C. H. Spurgeon, who felt the sting of its attacks, declared that "every good man is born for the love of God and the hatred of the Saturday." 4 Indeed, it was widely referred to as the "Saturday Reviler."

While the Saturday Review was not the only journal seen as subsuming the individual identities of its contributors, it is often singled out for its "unified voice, the voice of the educated upper middle class." ${ }^{6}$ Christopher Kent describes its special quality as something which "began to take on an independent and imposing identity of its own ... forcing the journalist to subordinate his own personality to that of the journal." 7 Merle Mowbray Bevington finds a remarkable uniformity in the style and ideas of the Saturday Review's writers, noting that "it presented the paradox of men of marked independence and individuality merged into a unity and consistency of tone and point of view so remarkable that it is possible to refer to what the Saturday said rather than to what a particular writer said in the Saturday." ${ }^{8}$ Contributors felt that they consciously changed their style when writing for the Saturday Review. Indeed, their experience seems to exemplify John Morley's remarks about the effect of anonymity 
on authors and the ability of a paper to generate a "spirit of its own, which enters into you when you take up your pen to write for it." ${ }^{9}$ Leslie Stephen reported that when he was looking through his own articles for the Saturday Review, he "was a little startled to discover that I could rarely distinguish them by internal evidence. I had unconsciously adopted the tone of my colleagues, and, like some inferior organisms, taken the colouring of my 'environment."' го

The development of quantitative measures of style gives us an opportunity to test the idea that writers adopted a distinctive style when contributing to the Saturday Review. In this study, we examined the work of six writers who contributed a substantial body of work to the Saturday Review as well as to other monthlies and quarterlies. We also identified some common characteristics of the Saturday Review's house style in order to illuminate what made it distinctive. We used two collections of periodical articles in our main analysis: the first group was comprised of 200 articles from monthlies and quarterlies generally considered to be "literary" periodicals, and the second was comprised of 220 reviews and "middles" from the Saturday Review. The Saturday Review articles were about the same length as the shortest articles in our group of other periodicals. As the name suggests, "middles" appeared after the leading article and before the book reviews. Saturday Review "middles" typically consisted of essays on social and moral subjects which began to take shape in the second half of I 858 , thereafter "increasing in cleverness and incisiveness." ${ }^{\text {II }}$ All of the articles in our corpus were either "middles" or reviews.

Since we excluded leading articles from our study, we believe that the articles we selected from the Saturday Review can be considered generic hybrids (essay-like reviews or review-like essays, for the purpose of our analysis, much like the articles from quarterlies and monthlies selected for comparison). ${ }^{\mathrm{I}}$ Table I lists the six writers in our study, each of whom published seven or more articles in the Saturday Review and other periodicals. ${ }^{\text {I3 }}$

Table 1. Six authors' article contributions to the Saturday Review and other periodicals.

Author

Walter Bagehot

Robert Cecil

G. H. Lewes

Eliza Lynn Linton

Anne Mozley

Leslie Stephen
Articles in the Saturday Review

I 6

38

I 7

27

I 6

I 5
Articles in other periodicals

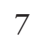

I 2

I I

7

20

9 
To determine if the Saturday Review indeed had a unique style that distinguished it from other literary periodicals, we turned to computational stylistics; in particular, we applied Principal Components Analysis (PCA) to frequencies of common words. PCA is a statistical technique that combines the counts of a number of specified individual variables to form new composite variables or "components." The aim of the method is to find a few components that account for a large amount of the overall variation in the original data set. In this sense, it is a data reduction technique designed to uncover a few important underlying factors in a dataset with a large number of variables. For each component, each word-variable has a weighting, much like a stock market index, which offers a single score incorporating dozens of individual prices, each with a weighting that reflects volume. The specimens have a score for each component, calculated by multiplying the frequency by the weighting for each variable and then finding the sum of these counts. These weightings and scores can then be shown in charts so that it is possible to see which specimens are clustered together or dispersed and which variables have played the largest part in determining these outcomes. It first finds the most important component (the first Principal Component) in a table of variables and specimens-in this case, word frequencies in articles or parts of articles—and then the second most important independent component, and so on. The use of PCA in combination with word frequencies has formed the basis of numerous studies of authorship, for example, to compare the different ways characters speak in novels and plays, to show the minute progression of Henry James's early and late works, and to determine the chronological order of plays. ${ }^{14}$ These methods have also been used extensively to categorize authors and eras. The fact that these results can be checked for reliability gives scholars confidence in situations where the method is used to argue for broader stylistic patterns. This is exactly what we were aiming to accomplish in this study.

We chose to count instances of common function words in the corpusthose that are more structural than meaningful, such as you, and, and the. At first glance, these words might seem an odd choice since they are inconspicuous and appear inert, serving merely a structural purpose. However, they have proven to be remarkably good markers of style, as Frederick Mosteller and David L. Wallace demonstrated in their attribution work during the I960s and as John Burrows illustrated in his analysis of style in the I980s. Numerous studies since Burrows's pioneering work have confirmed that patterns of functional words, though often overlooked by readers, provide insight into many dimensions of style, including authorship, genre, and historical time period. They are easily recognised and counted, unlike higher-order stylistic features, such as figures of speech, which need to be identified by hand. They can also be expected to appear in large num- 
bers even in short passages, offering almost sentence-by-sentence signals to the reader.

The articles included in our analysis varied in length from about 500 words to over 20,000 . We wanted to minimise any confounding factors based on length, so we divided the longer articles, all of those with $\mathrm{I}, 000$ words or more, and included the smallest ones, five in total, in their entirety so that no segment was less than 500 words or longer than 999. This yielded a set of I,658 segments, of which I,463 were exactly 500 words long. ${ }^{15}$ Dividing was the longer articles in this way also meant that internal stylistic variation was not averaged out, as it would have been if the article were considered as a whole, as is shown in the charts. Interesting anomalies could then be explored further.

We wanted a broadly based word list relating to Victorian journalism in general, so we selected the roo most common words in our total corpus of articles published in the Saturday Review and in monthly and quarterly periodicals (see appendix). ${ }^{16}$ We used these words as variables in a PCA test to determine the most important collective differences in the use of these words from group to group. Figure I shows the results of this analysis. ${ }^{17}$ The segments of the Saturday Review cluster to the right of the chart, with generally higher scores on the first Principal Component. The Saturday Review articles are thus distinguished from the rest on the basis of their use of the roo words. At this level of particularity, there are many segments of articles from other periodicals which are like those in the Saturday Review in terms of style and appear alongside them in the chart, but it seems fair to infer that the first Principal Component distinguishes the Saturday Review from its fellow periodicals. The stylistic distinctions are not stark-not on the scale one might expect, for example, when comparing one writer's work to another's-but a pattern is nonetheless clear. The data points with the highest scores are Saturday Review segments, most of which have scores greater than zero. The segments from the Saturday rarely appear in the lowest band of the range. ${ }^{18}$

Figure 2 shows the weightings for the word-variables for the first two Principal Components, the first and second most important components as determined by the procedure. ${ }^{19}$ Figures I and 2 correspond directly. High-scoring segments on a given Principal Component in figure I can be expected to have relatively high counts of word-variables with a high weighting on the same component in figure 2. Since segments from the Saturday Review tend to have high scores on the first Principal Component, we can assume that they have more instances of the words to the righthand side of figure 2 than do segments from other periodicals.

To explore the question of whether the Saturday Review's differences in word use (as revealed in figure I) are characteristic of weeklies in general, we prepared a small additional sample of ten articles from the Athenaeum 


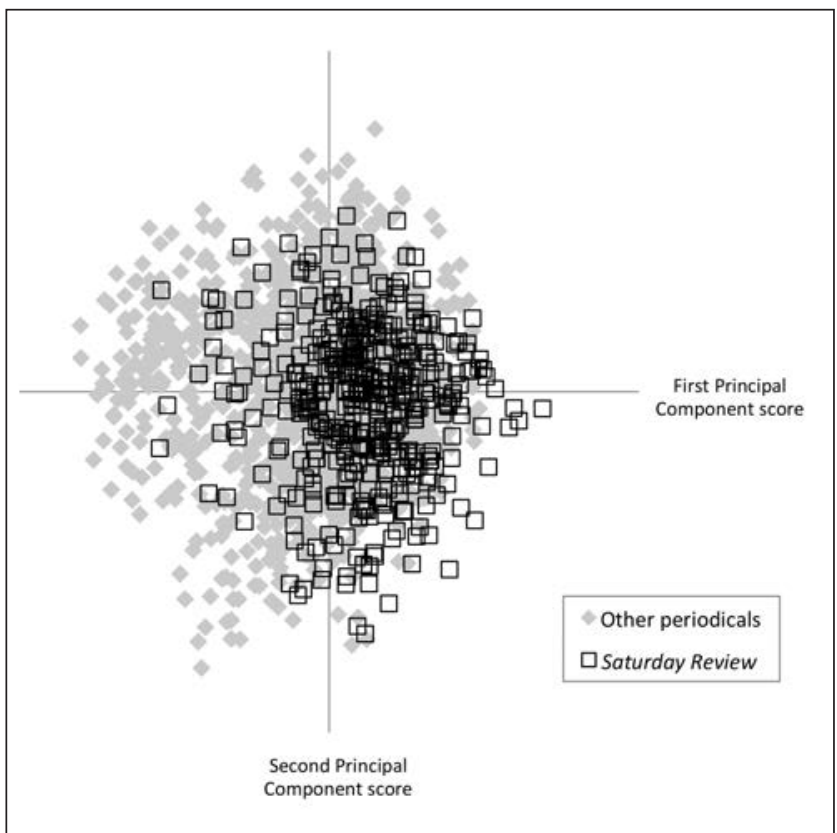

Figure I. Principal Components Analysis: One hundred very common words in I, 658 500 -word segments of articles in Victorian periodicals.

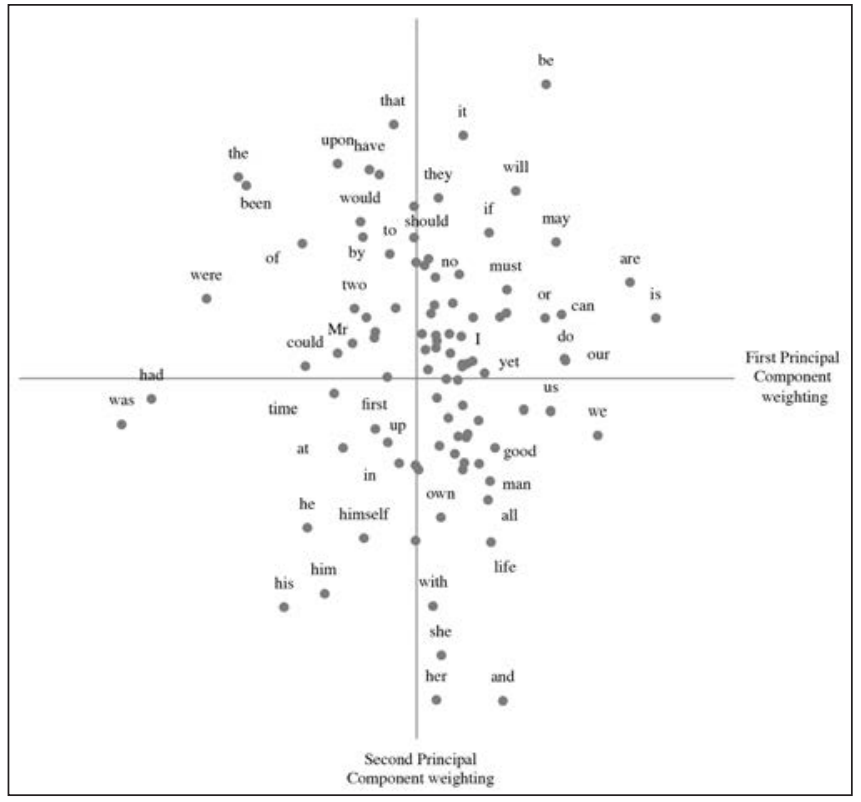

Figure 2. Word plot corresponding to the Principal Components Analysis in figure I. 
and fifteen from the Leader. ${ }^{20}$ Using the ten Athenaeum articles and ten chosen at random from both the Saturday Review and the Leader, as well as from the set of monthlies and quarterlies (in other words, four sets each of ten articles), we ran a PCA based on the Ioo very common words and then determined whether any of the three weeklies' scores on the first and second Principal Component were significantly different from the scores of the monthlies and quarterlies or from each other. ${ }^{2 \mathrm{I}}$ We repeated the test nine more times with random selections. In each of the ten trials, there were six comparisons, three for each Principal Component, thus sixty tests in all. The Athenaeum articles had significantly different scores from the monthlies and quarterlies, once on the first Principal Component and once on the second Principal Component; the Leader articles had different scores from the monthlies and quarterlies on the second Principal Component on two separate occasions; and the Saturday Review articles in one instance had different scores from the monthlies and quarterlies on the first Principal Component. The scores revealed no significant differences between the weeklies. We concluded that while generally the articles from weeklies were interchangeable with those drawn from the monthlies and quarterlies, there was some evidence that the three weeklies tested differed more from the monthlies and quarterlies than from each other. ${ }^{22}$ The "weekly effect," we concluded, would be important to investigate in future research.

Figure I shows that Saturday Review articles are different in style from the monthlies and quarterlies in terms of the frequency of very common words. Figure 2 allows us to identify the words that are most important in establishing this style. If we concentrate on the words to the right and left extremes of figure 2 , choosing the ten with the highest weighting and the ten with the lowest, we can make some preliminary observations about the characteristic style of the Saturday Review articles. ${ }^{23}$ First, they tend to have more present-tense verb forms (is, are, can, may, do, and be). The Saturday Review, it seems, was more topical than the monthlies and quarterlies and had a marked focus on current issues. Second, its articles have more firstperson plural pronouns (we, us, and our), which suggests that its contributors often assumed a common collective identity. Third, one conjunction, or, occurs more often in the Saturday Review than elsewhere. High counts of or in the articles occur where writers are sweepingly inclusive or insistently comprehensive, for example in the phrases "nothing useful, nothing good, nothing deep or true or holy" and "some oddness, or awkwardness, or passing slip in themselves or their accessories." ${ }_{24}$ Evidently, the Saturday Review articles have more of a tendency to multiply examples and possibilities than do most Victorian periodicals. Finally, there are indications of informality in the modal verb forms that appear on the right-hand side 
of figure 2: can, do, and may. In contrast, the articles in other periodicals are more often cast in the past tense (was, had, were, been, and could) and tend to offer specification and detail (the and of). The three masculine singular pronouns, his, he, and him, appear on the left-hand side of figure 2, suggesting that these articles focus more on a single male individual than do the Saturday Review contributions.

We next returned to the Athenaeum and Leader to explore whether they, like the Saturday Review, differed significantly from the monthlies and quarterlies. We confined ourselves to the twenty words with the highest and lowest scores on the first Principal Component in figure 2. Eight of these terms had significantly different scores in the Saturday Review articles than in the monthlies and quarterlies: are, $d o$, and is were higher, and could, had, his, was, and were were lower. ${ }^{25}$ When we checked the scores for these eight words in the Athenaeum and Leader sets, we found that two of them differed significantly from the results for monthlies and quarterlies in the Athenaeum set: is was higher and was was lower (as in the Saturday Review articles). None of the eight words were used differently in the fifteen Leader articles compared to the monthlies and quarterlies. The sample sizes for the Athenaeum and the Leader were small, and thus conclusions can only be tentative, but it would seem that the patterns apparent in figures I and 2 are not necessarily shared with other weeklies, although, as one might expect, they have some elements in common.

The segment that scored the highest on the first Principal Component in figure I was the third segment, words I,OOI to I, 500 of Anne Mozley's "Dulness as a Sensation," which appeared in the Saturday Review on August 9, I 862. Here Mozley generalises, adopts a plain and brisk style, assumes a shared viewpoint with the reader, asserts truths firmly and inclusively, and writes unequivocally about current issues. In the following extract from this segment, the ten words with the highest scores on the first Principal Component are underlined and bold-faced, and the ten with the lowest scores are capitalized and italicized. (The same conventions have been adopted for all longer quotations below.)

If it only meant not being diverted or exhilarated, dulness would be a weak subject $O F$ dread. But it is more. There is a foretaste, a threatening $O F$ something worse, a touch of undefined spiritual terrors in all dulness. A day $O F$ simple vacuity, $O F$ not being amused, has no analogy with THE dulness our active imagination realises. Everybody is now and then neither doing anything nor wanting to $\underline{\text { do }}$ anything unamused, and not wanting to be amused. Everybody is vacant sometimes, and does not dislike THE sensation; but what has all this to do with dulness? A man is dull, it may be, to other people, but not dull to himself. ${ }^{26}$ 
In contrast, the segment with the lowest score on the first Principal Component is Cecil's article in the Quarterly Review, "The Danish Duchies," which appeared in January I 864. Cecil writes impersonal history presented with an air of authority. He focuses on a past era, with events in the even more distant past marked with pluperfect tense. The highest and lowest weighted words on the first Principal Component have been marked as before:

Holstein, however, continued to retain its feudal relation to THE Emperor OF Germany. It remained a fief OF THE Holy Roman Empire till that empire WAS finally broken up in I 806 . Lauenburg WAS ceded to THE monarchy under a totally different title. When peace came after THE Great War, and those who $H A D$ languished long under THE oppression OF Napoleon came together to redistribute THE spoils they HAD won back from HIM, it WAS not likely that Denmark, who HAD joined HIM, would meet with much mercy from HIS victims. They WERE content, however, with stripping her OF Norway. By way OF compensation, THE petty Duchy OF Lauenburg, which lies upon THE south-eastern frontier OF Holstein, WAS added to THE Danish territory. At THE same time these two Duchies OF Holstein and Lauenburg, as they HAD formed part OF THE old German Empire, WERE included in THE new Germanic Confederation. ${ }^{27}$

None of the ten most positively weighted words occurs in this passage. Its hallmarks are firmness and precise specification as well as an insistence on firmly delineated past-tense verb forms. It has a singular male protagonist, Napoleon Bonaparte, with a corresponding high frequency of him and his.

Thus far we have been mainly concerned with the first Principal Component since this is where the contrast of the Saturday Review and the monthlies and quarterlies is evident. But analysis of the second Principal Component yields insight as well. We can sum up this second component as a contrast between segments with a preponderance of words reflecting impersonal argument and collective concerns (with high frequency of that, $i$, the and they) and segments focusing on individuals (with a high occurrence of her, she, his, him, and he). When we identified the genres, authors, and source journals of the segments at the two extremes of the second Principal Component, we found that political essays, particularly those by Cecil, had more of the impersonal words, and literary reviews, predominantly those by Linton and Mozley, had a greater preponderance of individualizing terms. These generic and authorial aspects take precedence over questions of the journal of origin. The second Principal Component does not divide Saturday Review articles from the others, for instance.

We also investigated the overall strength of the Saturday effect in periodical style by comparing it directly to the effect of differences between 
authors. We made up a series of fifteen sub-corpora, each with just two authors represented (each of the six authors matched with every other) and each with a mixture of Saturday Review articles and articles from other periodicals. In each of these sub-corpora, we found the number of words (out of the roo tested) that were significantly different when the sub-corpus was divided by author and the number that were different when it was divided between Saturday Review articles and the rest. ${ }^{28}$ We also formed three sub-corpora with randomly selected articles in order to provide a baseline of purely chance differences. The average number of words among the roo which were significantly different for the author pairs was 49.5 ; for the periodical types, 30.5 ; and for the random sets, I.I. ${ }^{29}$ Clearly, differences in individual authorial style were greater than stylistic differences in the Saturday Review and its fellow periodicals. It is nevertheless true that the Saturday-other contrasts yielded many more significant differences among word-variables than did random sets. The average for the random sets was about one, exactly what we would expect given the threshold of one per Ioo for chance results that we set for this test.

As previously noted, some authors claimed to have altered their usual way of writing to fit the corporate style of the Saturday Review. Our research methodology offered a way to explore whether this was true in actual practice. Figure I ignores authorship, marking segments only by their periodical source. Our test with the paired authors likewise did not consider whether authors' contributions to the Saturday Review were different in style than those they published elsewhere. We therefore created a second series of sub-corpora, grouping each author's segments separately this time in order to explore how many of the roo words were used at significantly different rates in Saturday Review articles than in those written for other periodicals. As before, we included some random sets to account for the kinds of differences that might occur by chance (figure 3 ). We discovered that each author indeed used words differently when writing for the Saturday Review than for other periodicals. Cecil used thirty-five out of the roo words tested differently, suggesting that he changed his style markedly when writing for the Saturday Review. At the other extreme was Lewes, who used just six of the words at different rates in his Saturday Review articles than in his other periodical publications. The average of words used differently for the random sets was around one, as before. Among the rest, Mozley had the next highest number after Cecil, then Linton and Stephen, and finally Bagehot, with fourteen of the roo words tested used at different rates in his Saturday Review articles than elsewhere.

We also analyzed possible changes in authorial style by returning to the Principal Components Analysis and considering the results by author. Figure 4 sums up the scatter of authorial segments along the first Principal Component axis. The extremes in terms of overall averages, as shown 


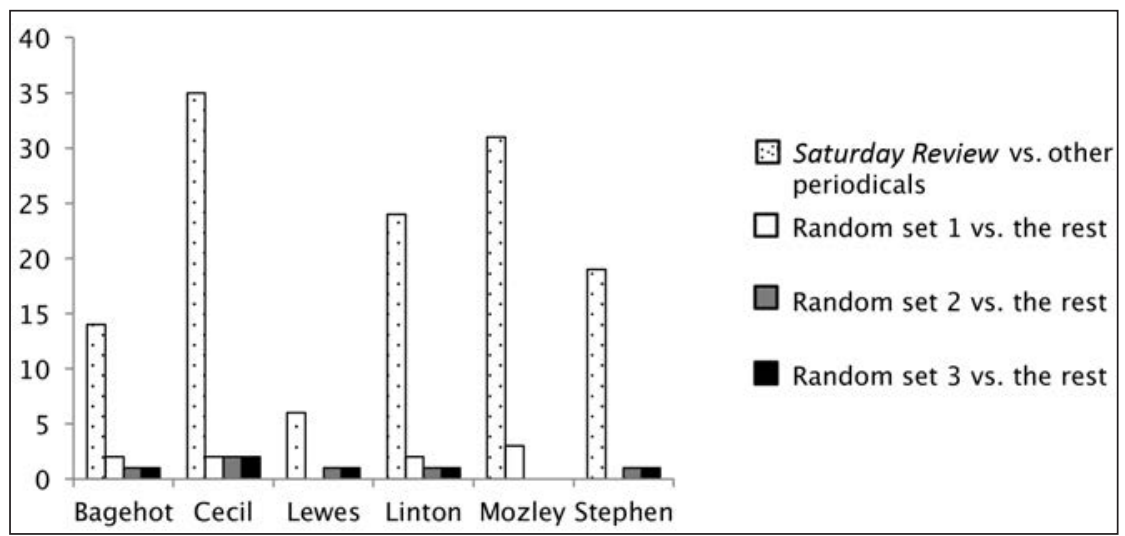

Figure 3. Number of word-variables in a set of Ioo with significantly different rates of use for Saturday Review articles and for articles from other periodicals in six-author sets.

in the lighter grey columns, are Cecil and Mozley. Cecil's segments are generally distinct in style from the rest of those in the Saturday Review, so the light grey column extends below the axis. However, his Saturday Review segments are very different from his segments for other periodicals. In general, his style does not resemble that of the Saturday Review, but he nevertheless does seem make some attempt to adapt to its house style. Mozley, on the whole, writes in a Saturday Review mode regardless of where she is publishing her work, but her samples do demonstrate that when she is writing for the Saturday Review, her style adopts its house style even more markedly. In contrast, Bagehot's and Lewes's styles only mildly resemble the Saturday Review's and do not change when they write for the review. Their Saturday Review segments have lower first Principal Component scores than segments published in other periodicals. Linton shows the greatest difference between her Saturday Review articles and her other periodical publications, as indicated by the tallest dark grey column on the graph. The full pattern is apparent if we look at her segments in the Principal Components Analysis on their own (figure 5). Here we identified segments of one Linton article, "Literature Then and Now," from the Fortnightly Review, April I, I 890, in order to show how widely one such piece can scatter across the chart. The second segment has the lowest score on the first Principal Component among all other sections in the article and is thus the furthest from the Saturday Review style. It offers an account of the practice of literature in medieval times-literature "then," as suggested by the article title-and is thus replete with definite articles and past-tense verbs.

It also focuses on a series of male scribes: 


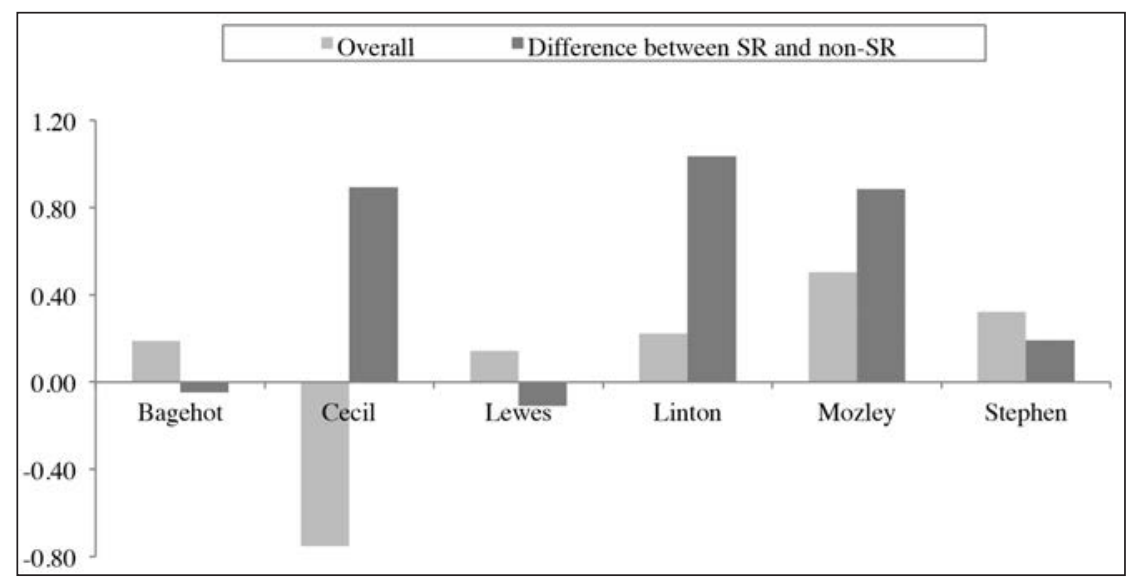

Figure 4. Extract from figure I showing overall averages of PCI score for six authors, and the difference between the score for Saturday Review articles and the score for articles in other periodicals for each author.

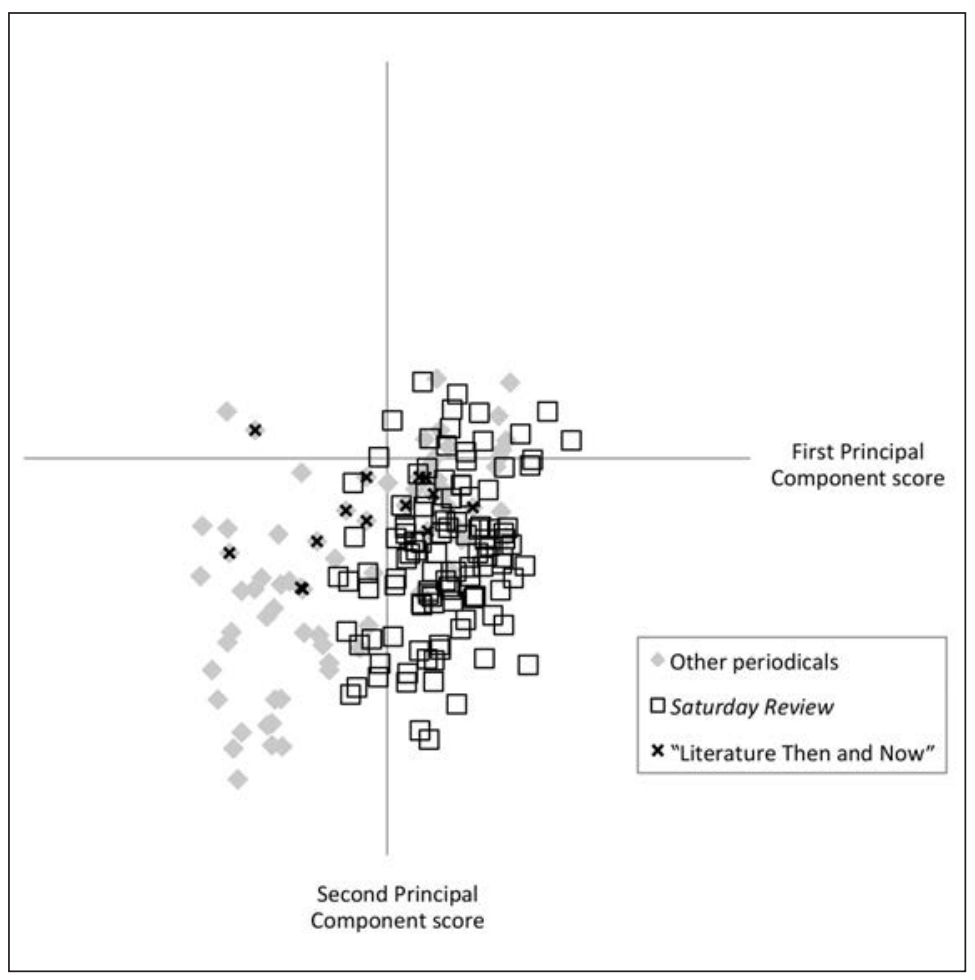

Figure 5. Extract from figure I showing only Linton's segments. 
In HIS quiet cell THE cloistered scribe copied and recopied HIS favourite manuscripts as THE lighter fringes OF THE religious life to which HE HAD dedicated himself. In THE hall, THE bard, who WAS also a vassal, celebrated $H I S$ seigneur's valiant deeds as part OF THE service $H E$ owed for protection. ${ }^{\circ}$

The thirteenth segment has the highest score, placing it at the heart of the Saturday Review cluster. It discusses literature "now," sensationalist literature, in particular:

These impossible manuscripts are for THE most part grotesque attempts at sensationalism or vapid sentimentalism. Sometimes they are essays OF THE cat's-cradle sort, where you look in vain for a central point or a leading line, and where there is neither orderly sequence OF idea nor THE sense OF proportion. OF all forms OF fiction THE sensational demands THE most careful treatment. There is but one step from THE sublime to THE ridiculous, and to THE sublime may be added THE horrible, THE eerie, THE bloodcurdling, THE sensational. That step is no wider than THE bridge, itself no thicker than a hair, over which THE True Believer passes on HIS way to heaven with THE pit yawning below. And just as many a peccant soul trips, stumbles, and falls, so do THE sensational writers pass over THE narrow line and plunge headlong into bathos. ${ }^{3 \mathrm{I}}$

What we have identified as the Saturday Review style appears in articles published in other periodicals, but in articles published in the Saturday Review this style predominates, sometimes in the extreme. As we have just seen, Linton occasionally writes in the Saturday Review style in her contributions to other periodicals. In her Saturday Review pieces, the characteristics of this style are more pervasive and marked. The first segment of her article "Interference," for example, has the highest score of any of her segments on the first Principal Component:

To be sure there are some men-small, fussy, finnicking fellows, with whom nature has made THE irreparable blunder OF sex-who are as troublesome in their endless interference as THE narrowest-minded and most meddling women $O F$ their acquaintance; but THE feminine characteristics $O F$ men are so exceptional that we need not take them into serious calculation. For THE most part, when men do interfere in any manly sense at all, it is with such things as they think they have a right to control—say, with THE wife's low dresses, or THE daughter's too patent flirtations. ${ }^{32}$

Linton's tone is confident and confidential; she provides a brisk survey of the topic and then establishes common ground with her readers by using "we" and employing a conversational style and diction. She deals with an 
uncomplicated present and presumes a shared common experience with her readers.

Our quantitative analysis of samples from Cecil, Linton, and Mozley supports the notion that the spirit of the Saturday Review changed some writers' characteristic writing style. Conversely, there was much less variation in the writing style of Lewes and Bagehot, which makes it difficult to distinguish their Saturday Review pieces from their writing for other periodicals. These findings support what we already know about these authors but also supplement and modify our views. Lewes, for example, was a professional bread-and-butter journalist whose extraordinary versatility brought him both admiration and disdain during his lifetime, writing, as he did, over 500 articles in a wide range of journals on an equally large range of topics. ${ }^{33}$ It would appear that there was almost no topic of interest in science, technology, literature, manners, or morals that Lewes was unwilling to tackle. Thus, it is not surprising to find that he had a defined style which is consistent across his various articles. Victorian readers sometimes commented on the ubiquity of the "omnipresent LEWES" and expressed a certain frustration at finding the work of the same unmistakable writer in various anonymous journals. ${ }^{34}$ It is also possible, as figure 4 suggests, that his usual style already shared some characteristics with the Saturday Review's, perhaps because it was highly topical and opinionated.

None of the other writers we studied maintained such an established voice and professional status. Although Bagehot and Stephen worked at times as journalists, Bagehot "made his income from a source outside journalism, as a banker" while Stephen was a fellow and tutor at Trinity Hall, Cambridge, before becoming editor of the Dictionary of National Biography in his later years. ${ }^{35}$ As previously noted, Stephen remarked on the fact that writing for the Saturday Review required an alteration of his usual style, and he objected to the fact that many of its writers argued viewpoints that disagreed with their private views. ${ }^{36}$ Robert Cecil, for example, wrote a group of anonymous articles in the Saturday attacking the women's movement, yet later, as prime minister, he supported women's suffrage. ${ }^{37}$ Because Cecil, Bagehot, and Stephen came to journalism from other professions, they were more likely to subordinate their writing style to the house style of the Saturday Review.

The two women writers in our sample were subject to different professional circumstances. Linton was the first woman to work as a salaried journalist in England, and as such, she was under particular pressure to adapt to the requirements of each assignment. When she applied for a job at the Morning Chronicle, editor John Douglas Cook gave her three and a half hours to write an article on the "condition of the miners under the 'truck' system," as detailed in a parliamentary commission's report. ${ }^{8}$ She was directed to "keep to the text; write with strength; and don't talk non- 
sense." ${ }_{9}$ She passed the test and wrote for the Chronicle for the next two years. Later she wrote what was perhaps the most-read article in the Saturday Review, the anti-feminist "The Girl of the Period" (I868). Mozley started writing for the Saturday in her fifties after working as an editor for her family's publishing firm and as a contributor to sectarian periodicals. Her specialty at the Saturday Review was writing articles on matters of everyday social interaction, what she called "social subjects" and "minor morals." $4 \circ$ As the stylistic analysis shows, this particular focus was accompanied by a change in style from her usual contributions to periodicals.

The frequencies of very common words like is, was, can, and the reflect language use at the level of bare structure, and a term like "stance" may be more appropriate for the patterns revealed than "style," with its suggestion of choices at all levels of syntax and diction. The notion of "stance" might help us understand how a particular periodical can maintain a recognisable house style. When writers took on the Saturday Review stance, some marked changes in word use followed. Or they just took on some of the conventions associated with what was considered suitable for a Saturday Review article. One can imagine Saturday Review writers being given a directive such as "Be clever, be cruel, be interesting, don't waste words-and above all, be amusing." Most authors, whatever their individual peculiarities, still adopted enough of the corporate focus, with its set of conventional usages, to imbue their articles with the Saturday Review identity. Some writers did not change their stance, choosing instead to retain their own well-established personal way of writing, perhaps because they felt less pressure to do so than others or because they were aware that their usual stance was at least compatible with the Saturday Review's approach.

Bevington's description of the Saturday Review's corporate style is enlightening. He observes that its enforced word limit for articles and its weekly publication cycle meant that writers had to forego the luxury of expository and argumentative writing, with their requirements of development and proof, and settle instead for providing a "feeling of authority and clear, hard, masculine economy and directness," thus offering an antidote to "fine writing" and "pompous verbosity." ${ }_{41} \mathrm{He}$ describes the adoption of an authoritative corporate stance by many authors in this way: "As self-appointed critics of English civilization, the Saturday Review reviewers of necessity assumed a pose of lofty condescension and infallibility which gave their utterances an oracular rather than an argumentative tone." ${ }^{2}$

The journal's affirmed policy of anonymity was vital to the notion of "general unity" which it claimed in its prospectus. As Bevington goes on to explain, this unity was only made possible by the entrepreneurial skills of its first editor, John Douglas Cook, who acted "as a buffer between the chief proprietor [A. J. B. Beresford Hope] and those of his staff whose principles in politics and religious matters were distinctly not Beresford 
Hopeian." ${ }_{43}$ Cook was generally able to achieve the "win-win" outcome he was seeking by assigning the subjects at hand "to writers who could write their own minds without going directly against the policy of the management." 44 This editorial sleight of hand meant that a number of talented but "wrongly" opinionated writers were prevented from writing "leader" articles, though they were given a relatively free hand in the "middles." Some of the distinctiveness of the Saturday Review segments must have come from Cook's corrections rather than from the more diffused spirit of the Saturday Review adopted by contributors. One contributor declared that the "editor's authority ruled every paragraph, directly disciplined or indirectly inspired every phrase," neatly suggesting the impossibly entangled mixture of editorial correction and authorial anticipation of this correction. ${ }^{45}$ Contemporaries pictured "proof sheets piled high as mountains" at Cook's country retreat in Cornwall, which testifies to the awe with which his editorial labours were regarded. ${ }^{46}$ On the other hand, as we have seen, the style of some authors changed much more than others when publishing articles in the Saturday Review. This suggests that editorial alterations are at best only part of the explanation for the consistency and distinctiveness of the Saturday Review's style. One might of course postulate that the editors were more ready to alter one writer's contributions than another's, but the pattern in figure 3 does not correlate with any obvious ranking of authors by status or gender. The women in the group, Linton and Mozley, show strong differences in their writing for the Saturday Review and for other periodicals, but the writing of one male contributor, Cecil, shows an even higher degree of difference. Among the men, there is no clear difference in status between Lewes and Bagehot, the two writers whose style changed little when moving from other journals to the Saturday Review, and Stephen and Cecil, whose style did change.

An empirical study of style illuminates the Saturday Review's relationship to the larger discourse to which it belonged-a vast, variegated periodical print culture. Our analysis indicates that the Saturday Review crystallised a new genre in the tradition of the Edinburgh Review pioneers. The sharp differentiation of styles among a select group of writers helps support Dallas Liddle's view that the Saturday Review was one of the Victorians' more remarkable experiments in recombining or reinventing genres and publishing forms, a cultural innovation which deserves to be put alongside the Waverley novels of Sir Walter Scott and Dickens's Pickwick Papers. ${ }^{47}$ Compared to articles published in other periodicals, contributions to the Saturday Review tend to be cast more often in the present tense, to speak in a corporate rather than individual voice, and to offer general pronouncements rather than detailed analyses. The representative Saturday article focuses on an undifferentiated "now" inhabited by "us." It is modishly direct and assertive and is impatient of pompousness or cant. 
Our study does not focus on defining the "slashing" aspect of the Saturday Review or its hostility to enthusiasm and sentiment, which was what most contemporary readers found striking-for example, the Cambridge undergraduates who read it at breakfast on Sunday "with a savage joy." 48 It is possible that this element would reveal itself in a stylistic study investigating a wider range of vocabulary focused on less common words, which might reflect more of the attitudes and preoccupations of the writers rather than the structure of their writing. Further work on the Saturday Review could well proceed in that direction. As already noted, another valuable step would be to expand the comparison of the Saturday Review with other weeklies (rather than just a range of quarterlies and monthlies). This might require a focus on a different set of writers, such as those with a substantial body of work in other weeklies as well as in the Saturday Review.

Centre for Literary and Linguistic Computing University of Newcastle, Australia

\section{Appendix: Principal Components Analysis}

Principal Components Analysis of roo very common words in I,658 500word segments of articles in Victorian periodicals. Weightings for the word-variables on the first and second Principal Components.

\begin{tabular}{|c|c|c|c|c|c|c|c|c|}
\hline & PCI & $\mathrm{PC}_{2}$ & & PCI & $\mathrm{PC}_{2}$ & & PCI & $\mathrm{PC}_{2}$ \\
\hline 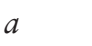 & O.I 58 & -O.I4 I & in & -0.044 & -0.140 & should & -0.006 & 0.235 \\
\hline all & 0.180 & $-0.20 \mathrm{I}$ & into & 0.004 & $-0.15 \mathrm{I}$ & so & O.II 5 & 0.019 \\
\hline$a n$ & 0.029 & 0.015 & is & $0.60 \mathrm{I}$ & 0.100 & some & O.II 2 & 0.070 \\
\hline and & 0.217 & -0.536 & it & O.II 7 & 0.405 & such & 0.107 & O.I74 \\
\hline any & -0.006 & 0.287 & its & 0.036 & 0.109 & than & O.II 6 & -0.045 \\
\hline are & 0.537 & 0.160 & life & O.I 87 & $-0.27 \mathrm{I}$ & that & -0.058 & 0.423 \\
\hline as & 0.120 & -0.139 & like & O.II 5 & $-0.15 \mathrm{I}$ & the & -0.448 & 0.335 \\
\hline at & -O.I 85 & -O.I I 4 & little & 0.079 & -0.065 & their & 0.030 & 0.199 \\
\hline be & 0.325 & $0.49 \mathrm{I}$ & made & $-0.16 \mathrm{I}$ & 0.058 & them & O.I 42 & 0.102 \\
\hline been & -0.428 & $0.32 \mathrm{I}$ & man & O.I 84 & -0.170 & there & 0.209 & 0.103 \\
\hline but & O.II 5 & 0.024 & many & 0.045 & 0.122 & these & 0.023 & 0.048 \\
\hline by & -0.135 & 0.235 & may & $0.35 \mathrm{I}$ & 0.227 & they & 0.055 & 0.301 \\
\hline can & 0.364 & 0.106 & men & O.I4 I & 0.029 & this & 0.125 & -0.097 \\
\hline could & -0.280 & 0.020 & might & -0.126 & O.IOI & those & -0.002 & 0.193 \\
\hline do & 0.375 & 0.030 & more & 0.085 & 0.042 & time & -0.208 & -0.025 \\
\hline even & $0.05 \mathrm{I}$ & 0.063 & most & 0.104 & -0.003 & to & -0.067 & 0.207 \\
\hline every & 0.128 & 0.025 & $M r$. & -0.199 & 0.042 & two & -0.157 & O.II 7 \\
\hline first & -0.104 & -0.083 & much & 0.074 & $-0.00 \mathrm{I}$ & under & -0.107 & 0.068 \\
\hline for & $0.05 \mathrm{I}$ & -0.032 & must & 0.227 & O.I 48 & $u p$ & -0.073 & -0.105 \\
\hline from & -0.104 & 0.078 & no & 0.048 & 0.169 & upon & -0.198 & 0.358 \\
\hline good & O.I97 & -O.II 5 & not & 0.226 & 0.109 & $u s$ & 0.337 & -0.054 \\
\hline
\end{tabular}




\begin{tabular}{|c|c|c|c|c|c|c|c|c|}
\hline & PCI & $\mathrm{PC}_{2}$ & & PCI & $\mathrm{PC}_{2}$ & & PCI & $\mathrm{PC}_{2}$ \\
\hline great & -0.053 & O.II 7 & now & 0.049 & 0.072 & very & 0.014 & 0.074 \\
\hline had & -0.667 & -0.034 & of & -0.287 & 0.225 & was & -0.742 & -0.076 \\
\hline has & 0.092 & 0.125 & on & -0.003 & -0.143 & we & 0.455 & -0.094 \\
\hline have & -0.1 I 9 & 0.348 & one & 0.105 & -0.095 & were & -0.529 & 0.133 \\
\hline be & -0.275 & -0.247 & only & 0.049 & $0.05 \mathrm{I}$ & what & 0.270 & $-0.05 \mathrm{I}$ \\
\hline her & 0.049 & -0.535 & or & 0.323 & O.IOI & when & -0.003 & -0.269 \\
\hline him & $-0.23 \mathrm{I}$ & -0.357 & other & 0.019 & 0.189 & which & -0.094 & 0.340 \\
\hline himself & -0.133 & -0.265 & our & $0.37 \mathrm{I}$ & 0.033 & who & 0.097 & -O.I 24 \\
\hline his & -0.333 & -0.380 & out & 0.057 & -O.I I I & will & 0.250 & 0.313 \\
\hline how & 0.129 & $-0.09 \mathrm{I}$ & own & 0.060 & -0.230 & with & $0.04 \mathrm{I}$ & -0.378 \\
\hline$I$ & 0.082 & 0.075 & same & -0.074 & 0.002 & without & 0.156 & -0.069 \\
\hline if & 0.183 & 0.243 & she & 0.062 & -0.460 & would & -0.142 & 0.262 \\
\hline & & & & & & yet & O.I7I & 0.009 \\
\hline
\end{tabular}

\section{NOTES}

I. Linton, "Literature: Then and Now," 52 I.

2. Jump, "Weekly Reviewing," 253, 254.

3. White, London, 243; Liddle, Dynamics, 60, I66.

4. Quoted in White, London, 243.

5. Bevington, Saturday Review, 44, 7 I.

6. Tilley, "Saturday Review."

7. Kent, "Higher Journalism," I92.

8. Bevington, Saturday Review, 34.

9. Quoted in Kent, "Higher Journalism," I92; originally from "Anonymous Journalism," published in the Fortnightly Review in September I 867.

го. Stephen, Some Early Impressions, I30.

II. Ibid., 24-25.

I2. In "The First Edinburgh Reviewers," Walter Bagehot describes the emergence of this genre of "essay-like criticism," which presented "large topics of suitable views for sensible persons" (7). This genre was founded by the Edinburgh Review and later adopted by other periodicals. As one of our peer reviewers pointed out, the exclusion of leaders from our corpus also means that our analysis of patterns of style in the Saturday does not necessarily extend to the style of the leaders in the journal.

I3. The details for each of these articles can be found on the Centre for Literary and Linguistic Computing website (University of Newcastle, Australia): http://www.newcastle.edu.au/research-and-innovation/centre/education-arts/ cllc/publications.

I4. Burrows, Computation into Criticism; Craig, "Speak, That I May See Thee"; Hoover, "Corpus Stylistics"; Craig, "The Date of Sir Thomas More." 
I 5. The Saturday Review articles are shorter than the ones from other periodicals and yield fewer segments even though there are more of them, 422 compared to I,236.

I6. The larger corpus included 200 quarterly and monthly articles as well as the 220 Saturday Review articles used in our analysis, together totaling 2.7 million words. A list of the Ioo most common function words of this corpus can be seen in the appendix. Readers may be interested to know how much difference the corpus makes to such a list. If we use the smaller corpus (consisting only of articles by the six authors discussed here) to make a I००-most-common-words list, we find three words come in, being, never, and too, and three words go out, how, $I$, and under.

I7. The first Principal Component accounts for 5.0 percent of the total variance in the original table; the second Principal Component accounts for 4 .I percent of the total variance.

I 8. The point biserial correlation (for PCI and a dummy variable, Saturday Review $=\mathrm{I}$, other $=2$ ) is $-0.25, \mathrm{p}<.000 \mathrm{I}$.

I9. Some labels in the chart have been omitted for clarity. The appendix gives a full listing of the word-variables and their weightings on the first two Principal Components.

20. The details for each of these articles can be found on the Centre for Literary and Linguistic Computing website (University of Newcastle, Australia): http://www.newcastle.edu.au/research-and-innovation/centre/education-arts/ cllc/publications.

2I. We used Student's t-test and a significance threshold of $\mathrm{p}<$. . I I. Student's $\mathrm{t}$-test indicates whether the difference in mean between two groups of specimens reflects a genuine, consistent difference or merely a chance effect arising from fluctuating counts. Given the number of samples considered, we can calculate a probability that the two groups derive from the same parent population (i.e., that they are not any more different than random variation would indicate). See Urdan, Statistics, 93-IO4.

22. In five of the sixty comparisons, there were significant differences between a weekly journal and the monthlies and quarterlies; correspondingly, in fiftyfive of the comparisons, there were no significant differences.

23. The highest-scoring words associated with the Saturday Review segments are: is, are, we, our, do, can, may, us, or, and be. The lowest-scoring words associated with the segments from other journals, starting with the lowest, are: was, had, were, the, been, his, of, could, he, and him.

24. Linton, "Fashionable," I 85 ; Mozley, "False Shame," 4I.

25. We again used the t-test and a significance threshold of $\mathrm{p}<$. . I.

26. Mozley, "Dulness," 73.

27. Cecil, "Danish Duchies," 237. Cecil's article is from the Quarterly Review, which espoused Tory political views. It is tempting to suspect that this political outlook might be reflected in some aspects of the style of its articles. 
Antonia's dissertation, however, presents evidence that the various quarterlies were essentially homogenous in style, despite their differing ideologies.

28. We used the t-test as before to determine significant differences between groups of articles for a given word-variable, with a threshold of $\mathrm{p}<. \mathrm{OI}$.

29. In each of the fifteen trials, the author-contrast method produced more significantly different words than the periodical-type approach, though the difference in one case, Lewes versus Linton, was only 38 to 36.

30. Linton, "Literature," 5 I 8.

3I. Ibid., 528-29.

32. Linton, "Interference," $84 \mathrm{I}$.

33. Brake, "Literary Criticism," 94; Ashton, Versatile Victorian, I-3.

34. Brake, "Literary Criticism," I I I.

35. Ibid., 94 .

36. This was also shown when contributors to the Saturday Review were forced to attack liberal theology or write in support of the Confederacy during the American Civil War. Maitland, Life and Letters of Leslie Stephen, I66, 200.

37. Antonia and Jordan, "Who Wrote."

38. Bevington, Saturday Review, I4.

39. Ibid., I 5 .

40. Quoted in Jordan, "Sister as Journalist," 324.

4I. Bevington, Saturday Review, I4, 32 I.

42. Ibid., 4I.

43. Ibid., 34 .

44. Ibid., 35 .

45. Quoted in Bevington, Saturday Review, 38.

46. Ibid., 39.

47. Liddle, Dynamics, 8.

48. Besant, Autobiography, 94.

\section{BIBLIOGRAPHY}

Antonia, Alexis. "Anonymity, Individuality and Commonality in Writing in British Periodicals—I830 to I 890: A Computational Stylistics Approach.” PhD diss., University of Newcastle, 2009.

Antonia, Alexis, and Ellen Jordan. "Who Wrote the Women's Movement Articles in the Saturday Review?" Nineteenth Century Gender Studies 4, no. 3 (2008). http://ncgsjournal.com/issue43/antonia.htm.

Ashton, Rosemary, ed. Versatile Victorian: Selected Critical Writings of George Henry Lewes. Bristol: Bristol Classical Press, I992.

Bagehot, Walter. "The First Edinburgh Reviewers." I 855 . Reprinted in The Works of Walter Bagehot, edited by Forrest Morgan, I:I-44. Hartford: Travelers' Insurance Company, I 89I.

Besant, Sir Walter. Autobiography. I902. Reprint, St. Clair Shores: Scholarly Press, I97I. 
Bevington, Merle Mowbray. The Saturday Review, I 855-I868: Representative Educated Opinion in Victorian Britain. New York: AMS, I966.

Brake, Laurel. "Literary Criticism and the Victorian Periodicals." Yearbook of English Studies I6 (I986): 92-II6.

Burrows, John. Computation into Criticism: A Study of Jane Austen and an Experiment in Method. Oxford: Clarendon, I987.

Cecil, Robert. “The Danish Duchies.” Quarterly Review I I 5 (January I 864): $236-87$.

Craig, Hugh. "The Date of Sir Thomas More." Shakespeare Survey 66 (2013): $38-54$.

—. "'Speak, That I May See Thee': Shakespeare Characters and Common Words." Shakespeare Survey 6I (2008): 28 I-88.

Hoover, David. "Corpus Stylistics, Stylometry, and the Styles of Henry James." Style 4I (2007): I74-203.

Jordan, Ellen. "Sister as Journalist: The Almost Anonymous Career of Anne Mozley." Victorian Periodicals Review 37, no. 3 (2004): 3 I 5-4 I.

Jump, J. D. "Weekly Reviewing in the Eighteen-Sixties." Review of English Studies 3, no. II (I952): 244-62.

Kent, Christopher. "Higher Journalism and the Mid-Victorian Clerisy." Victorian Studies I3 (I969): I 8I-98.

Liddle, Dallas. The Dynamics of Genre: Journalism and the Practice of Literature in Mid-Victorian Britain. Charlottesville: University of Virginia Press, 2009.

Linton, Eliza Lynn. “The Fashionable Woman.” Saturday Review 26 (August 8, I 868): I 84-86.

—. "The Girl of the Period." Saturday Review 25 (March I4, I868): 33940 .

"Interference." Saturday Review 25 (June 27, I 868): 24 I-42.

. "Literature: Then and Now." Fortnightly Review 47, n.s. (April I 890): 5I7-3I.

Maitland, Frederic William. The Life and Letters of Leslie Stephen. London: Duckworth, I906.

Mosteller, Frederick, and David L. Wallace. Inference and Disputed Authorship: The Federalist. Reading, MA: Addison-Wesley, I964.

Mozley, Anne. "Dulness as a Sensation." Saturday Review I4 (August 9, I862): I 56-57.

—. "False Shame." Saturday Review I2 (September 28, I86I): 322-23.

Stephen, Leslie. Some Early Impressions. London: Hogarth Press, I924.

Tilley, Elizabeth. "The Saturday Review." In The Dictionary of NineteenthCentury Journalism, edited by Laurel Brake and Marysa Demoor. London and Ghent: British Library and Academic Press, 2009. http://ocr 9index.chadwyck. co.uk.library.newcastle.edu.au/fullrec/fullrec. $d o$ ? id= I $276 \&$ forward=search \&a rea $=$ dncj.

Urdan, Timothy C. Statistics in Plain English. $3^{\text {rd }}$ ed. New York: Taylor and Francis, 2OII.

White, Jerry. London in the Nineteenth Century. London: Cape, 2008. 